\title{
Renegotiating Identity and Relationships: Men and women's adjustments to retirement
}

\author{
Helen Barnes and Jane Parry
}


PSI Research Discussion Paper 14

\section{Renegotiating Identity and Relationships: \\ Men and women's adjustments to retirement}

Helen Barnes and Jane Parry

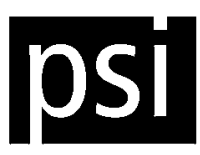

Policy Studies Institute 
(c) Policy Studies Institute, 2003

All rights reserved. No part of this publication may be reproduced, stored in a retrieval system or transmitted in any form or by any means, electronic or otherwise, without the prior permission of the copyright holder.

ISBN: 0853748128

PSI Report No: 892

\section{pSi}

Policy Studies Institute

For further information contact

Publications Dept., PSI, 100 Park Village East, London NE1 3SR

Tel: (020) 74680468 Fax: (020) 74682211 Email pubs@psi.org.uk

PSI is a wholly owned subsidiary of the University of Westminster 


\title{
Renegotiating Identity and Relationships: \\ Men and women's adjustments to retirement
}

\author{
Helen Barnes and Jane Parry
}

\author{
Helen Barnes and Jane Parry \\ Policy Studies Institute \\ 100 Park Village East, London NW1 3SR \\ h.barnes@psi.org.uk \\ j.parry@psi.org.uk
}

\section{Abstract}

Retirement is frequently a period of change, when the roles and relationships associated with individuals' previous labour market positionings are transformed. It is also a time when personal relationships, including the marital relationship and relationships with friends and family, come under increased scrutiny and may be realigned. Many studies of adjustment to retirement focus primarily on individual motivation; by contrast, this paper seeks to examine the structure of resources within which such decisions are framed. The paper examines the contribution that gender roles and identities make to the overall configuration of resources available to particular individuals. It draws upon qualitative research conducted with older people in four contrasting parts of the UK, looking at the combination of labour market and non-labour market activities they are involved in prior to reaching state retirement age, as they 
withdraw from paid work. It explores how older people invoke a range of gendered identities to negotiate change and continuity during this time. The paper argues that gender roles and identities are central to this process and that the reflexive deployment of gender may rank alongside financial resources and social capital in its importance to the achievement of satisfying retirement transitions. Amongst those interviewed, traditional gendered roles predominated, and these sat less comfortably with retirement for men than for women.

\section{Key words/expressions:}

Gender, identity, marriage, non labour market activities, paid work, relationships, retirement 


\section{Introduction}

As people move into retirement and assume greater or lesser degrees of detachment from the work they have performed for much of their lives, they engage with a series of adjustments in their routines, relationships and expectations. With the loss of paid work, existing roles and identities come under increased scrutiny and pressure, and are likely to undergo substantial change in response to new constellations of resources, such as time, money, personal space, health status and social networks. Gender roles and identities are central to this process. Women and men have different patterns of lifetime employment, vary in their friendship and other social networks, and have particular patterns of engagement with caring roles within the family. Thus gender is an important influence on how individuals adapt to retirement and the quality of life achieved during this phase of the lifecycle.

Men, particularly when they have developed strong occupational attachments, and have fewer non-work routines and networks than women, may find this transition problematic, causing frustrations in the domestic sphere. Relationships often come under intense scrutiny during this period, resulting in polarised positive and negative outcomes, including enhanced marital satisfaction or divorce. Retirement and preparation for retirement may also prompt the development of a new series of social networks, drawing upon attachments based in religious, voluntary, community or leisure associations. For some, this process entails a natural consolidation of pre-retirement activities, while for others the acquisition or extension of fulfilling relationships 
requires a more concerted effort. By contrast, retirement may be a time when social networks are curtailed and individuals experience a heightened sense of isolation due to declining health, lack of money, caring responsibilities, bereavement, or geographical restrictions.

This paper draws upon research conducted with older people approaching retirement or already retired in four parts of the UK (Barnes et al. 2002). It considers the effects of the adoption of certain gender roles upon retirement, and examines differences between men and women, exploring the extent to which roles and identities are traditional or more egalitarian, fixed or more flexible, and the consequences of this for individuals and their relationships.

\section{Background}

Richardson's seminal study of male retirement (1956) found that people generally experienced mixed feelings about leaving work. These attitudes were influenced by health, meanings attached to former jobs, how long people had been retired, time use in retirement, and relationships with family and friends. These were confirmed by Crawford's research (1972), which found some couples perceived retirement as a time of crisis. Recent years have seen a heightened recognition of the retirement transition as a critical phase in the family lifecycle (Szinovacz et al. 1992), attracting interest from life course perspectives (George 1993, Moen 1996). Slevin and Winsgrove (1995) 
identified five factors consistent across the American literature as determinants of retirement satisfaction: self-perceived health, financial security, retirement planning, participation in activities, and marital status.

Role theory (Parsons 1942) provides a way into these issues, its premise being that difficulties adjusting to retirement stem from loss of status and identity associated with leaving paid work. This is particularly relevant for men belonging to social groups organised around breadwinner expectations (often in areas with little 'female' employment), and to people strongly attached to particular occupations. Corresponding research (Tibbitts 1954) suggested that because of weaker attachments to the labour market and pre-existing domestic roles, women find retirement less stressful. However, this research is dated and fails to take into account growth in female employment. Nevertheless, women typically perform qualitatively different paid work to men, being more heavily represented in low-paid and part-time positions, and displaying fragmented career trajectories (Bottero 2000), which is likely to inform how they adjust to retirement. On one level, less fixed employment expectations may mean women find the financial and lifestyle transitions involved in retirement less problematic. By contrast, Szinovacz (1991) suggests that women find leaving paid work more difficult because, having taken breaks to raise families, they have devoted less time to careers, and may feel they have achieved fewer employment goals. These experiences will be mediated by class differences. 
The literature has tended to focus on work in relation to retirement, overlooking people's experiences where paid employment has been a less important aspect of their identity. This paper argues for a more inclusive recognition of the non-labour market activities men and women take part in over their lifetimes, the changes or continuities accompanying retirement in these respects, and the role of participation in these activities in terms of older people's identifications, relationships, and well being. It draws upon findings from a project (Barnes et al. 2002) which examined older people's transitions into retirement, looking at the ways in which their participation in paid work, voluntary, community, leisure and family-related activities was negotiated during this point in their life. Qualitative interviews were conducted with 48 men and women aged 50-65 engaged in little or no paid work in four contrasting areas of the UK, to consider how different occupational, social and economic profiles affect people's circumstances in leaving employment, in addition to their options in retirement. Areas for study were selected using ACORN classifications $^{1}$ and small area statistics to identify regions with distinctive demographic and socio-economic characteristics and to distinguish suitable localities for study. These were: a suburban part of Scotland; an inner city area of London; a former coalmining village in South Wales; and a rural town in South West England. The localities in London and South Wales were characterised by high levels of unemployment and disability or ill-health, although they possessed very different labour markets and other demographic characteristics. These contrasted in particular with the area in South West England, which was relatively affluent. The Scottish locality was characterised 
by a set of socio-economic conditions closer to the national average, albeit that a higher proportion of the over fifty age group lived there.

A screening questionnaire was sent to around 500 addresses in each area, to recruit people in a variety of circumstances. Returned questionnaires were used to systematically fulfil quotas (in terms of age, gender, ethnicity, health, current activities and household composition) in these areas, and where there was an insufficient response from a particular category (such as volunteers), these were recruited using local contacts such as places of worship, charity shops, volunteer bureaux and community centres (snowball sampling). Some of the characteristics of the interview sample are presented in Table 1.

Table 1: Interviewees' characteristics

\begin{tabular}{lllll}
\hline & East & Hackney & Onllwyn & Warminster \\
& Renfrewshire & (inner-city & (south Wales & (rural south- \\
(suburban & London) & valleys) & west England) \\
& Scotland) & & & \\
\hline Gender & 7 women & 8 women & 6 women & 6 women \\
& 5 men & 4 men & 6 men & 6 men \\
Ethnicity & All White & 2 Black & All White & All White \\
& & Caribbean & & \\
& & 2 Asian & & \\
Social & 4 working & 7 white & & \\
\hline
\end{tabular}




\begin{tabular}{|c|c|c|c|c|}
\hline \multirow[t]{2}{*}{ Class $^{2}$} & class & class & class & \\
\hline & 8 middle class & 5 middle class & 5 middle class & 10 middle class \\
\hline Marital & 8 married & 7 married & 10 married & 11 married \\
\hline \multirow[t]{2}{*}{ status } & 2 divorced & 4 divorced & 2 divorced & 1 divorced \\
\hline & 2 widowed & 1 single & & \\
\hline \multirow[t]{5}{*}{ Current } & 6 retired & 4 retired & 5 retired & 8 retired \\
\hline & 4 some paid & 3 some paid & 1 some paid & 3 some paid \\
\hline & work & work & work & work \\
\hline & 2 disabled/ & 5 disabled/ & 6 disabled/ & 1 disabled/ \\
\hline & long-term sick & long-term sick & long-term sick & long-term sick \\
\hline \multirow[t]{2}{*}{ Age } & 5 fifties & 5 fifties & 6 fifties & 6 fifties \\
\hline & 7 sixties & 7 sixties & 6 sixties & 6 sixties \\
\hline \multirow[t]{9}{*}{ Activities } & 9 family & 7 family & 6 family & 9 family \\
\hline & responsibilities & responsibilities & responsibilities & responsibilities \\
\hline & 12 leisure & 12 leisure & 12 leisure & 12 leisure \\
\hline & 4 community & 6 community & 7 community & 3 community \\
\hline & activities & activities & activities & activities \\
\hline & 4 informal & 9 informal & 6 informal & 6 informal \\
\hline & voluntary work & voluntary work & voluntary work & voluntary work \\
\hline & 5 formal & 6 formal & 6 formal & 9 formal \\
\hline & voluntary work & voluntary work & voluntary work & voluntary work \\
\hline
\end{tabular}

Fieldwork was conducted using semi-structured depth interviews, which drew upon a topic guide covering personal information, family and social 
relationships, paid and unpaid work, community and leisure activities, and future hopes and plans. Topic guides were employed flexibly to derive comparative information, and in addition, researchers probed on people's diverse circumstances and priorities. Interviews focused upon the experiences of a named individual within each household, and in a number of interviews partners joined in during particular parts of the interview to discuss or elaborate on particular issues. At the end of each interview, interviewees were presented with two vignettes (from seven available), which dealt with issues such as how to cope with caring responsibilities, couples' renegotiation of their expectations of one another, and dealing with bereavement. This method drew out group norms and their influences on individual decision-making processes, but also provided a safe environment in which informants could comment on potentially sensitive issues, creating a degree of distance between themselves and the protagonists' dilemmas.

All interviews were taped and transcribed and analysed using QSR $\mathrm{NVivo}^{3}$, using a combination of open and thematic coding, and the software's 'set' facility was utilised to draw out similarities and contrasts between areas. The assignment of 'attributes', such as social class and age, to individual transcripts enabled the relationships between socio-economic circumstances and individual experiences of retirement to be examined. Once the dataset was complete and familiar to researchers, analysis of individual transcripts allowed more subjective attributes to be assigned to informants' experiences, based upon a whole range of experiences and attitudinal information across 
time and in relation to one another, such as 'ease of transition to retirement' and 'gender identity'.

This paper examines the above issues in terms of four main sections, which consider gender roles and resources in terms of: moving into retirement and reworking identity, older people's friendships, adjusting to retirement and its effects upon marriage, and single people and retirement. Quotations from the interviews are used to illustrate these discussions, and unless otherwise stated, where individuals are quoted, the issues raised represent a common theme. All names presented here are pseudonyms to protect the identities of the individuals who were interviewed.

\section{Moving into retirement and reworking identity}

Whereas retirement has previously been conceptualised in terms of the loss of a social role, it is now more widely recognised that it entails the opportunity to acquire new roles (such as volunteer or part-time worker), and to continue in other roles (such as parent or friend) (Reitzes et al. 1998). However, dominant cultural values persistently prioritise paid work and attribute it a central role in identity formation. Thus movements into retirement are frequently experienced in terms of tension, loss, reluctance and failure (Phillipson 1993), especially where individuals are strongly attached to occupations. 
Movements into retirement may be voluntary or involuntary, and occur abruptly or over a longer period. Choice is generally recognised to be a key determinant of satisfaction, although the literature suggests that its effects diminish over time as individuals adjust to their situation (George and Maddox 1977, Isaksson and Johansson 2000). The centrality of work is another key factor, and gender differences in the decision to retire and adjustment to retirement are often attributed to women's generally lower attachment to their jobs (Richardson and Kilty 1991). However, many analyses of retirement behaviour, modelled on a work/non-work dichotomy more applicable to men, neglect other aspects of retirement decisions, particularly those relating to family care (Isaksson and Johansson 2000).

Work provides a plurality of functions and rewards, including purposeful activity, sociability, status, and material gain. Individuals attach different significance to these and prioritise them differently over the lifecycle. Work also provides a series of routines giving structure and meaning to people's lives, upon which they rely more or less heavily. Consequently the loss of paid labour, in the context of structural positioning and social involvement, affects people in different ways. Gender is an important dimension in this process, since women's employment biographies have typically been more fragmented then men's, including time taken to raise children or care for parents. Men's frequently more intensive employment patterns also have implications for the character of their social networks. 
While interviewees were at different stages of detachment from the labour market, from still working to not having worked for twenty years, their 'distance' from paid work emerged as less relevant to how they adjusted to retirement than their personal attitudes and circumstances. The majority expressed ambivalence about leaving paid work, describing a mixture of regret and gladness when they first left, and issues coming to terms with changes of routine and finances.

Men with strong attachments to their jobs often found it hard to cope with losing this work, particularly when they had little choice and left before they felt ready. Indeed work had been central to most of the men interviewed. Mr Rutherford expressed feelings of 'loss' and 'anger' about his redundancy from the bank he had managed. This had not caused financial problems; he had obtained satisfying bridge employment, and had many interests outside work. However, the position had been central to his identity, particularly as he lived in a small place where most people knew one another, and he conceptualised the loss of this role as detrimental to his whole family.

A strong attachment to particular jobs was often associated with maleidentified occupations, and came out strongly in the former coalmining village. The transition away from paid work in such 'occupational communities' can be particularly difficult. Work acted as a focal point around which broader identity processes were formulated, including political and communal attachments, and a prescriptive set of masculinities and femininities based upon separate spheres (Massey 1995, Parry 2000). Mr Robertson was one among many who 
missed the camaraderie and sense of purpose of coalmining. He had been devoted to his work and, a former shift worker, remained unable to sleep at night six years after retiring. He lacked purpose, was uninterested in voluntary work, and increasingly spent his time bored at home. By contrast, his wife experienced few problems adjusting, largely because having adopted the expected family care and 'servicing' of her husband's occupation in the domestic sphere, retirement made little difference to her identity or daily routines.

Some women also referred to missing work, although they were more likely to miss social aspects and to stay in touch with former colleagues. The minority of women who expressed a strong identification with their work found it painful to retire. For Mrs Barber, a former teacher, retirement was triggered by reaching sixty and by her husband's health problems. She had not felt 'ready to leave', and described losing her job as 'a bereavement', saying that she had 'cried for weeks,' and could not bear to return to her former school and see someone else in 'her' classroom. Mrs Ramsay, unusually amongst the female informants, expressed her work identity in terms of a 'worker' and 'provider', which related both to her status as a lone parent and the 'work ethic' her own parents had adopted. She reported feeling 'devastated' when ill health forced her to leave.

By contrast, some men who had expressed considerable pleasure and satisfaction in their work and felt it to be central to their identity, had experienced no great sadness at leaving, sometimes to their surprise. Key 
factors influencing their feelings included choice, a reasonable level of income, and the prospect of enjoyable activities in retirement. For instance, Mr Kamir expressed his pleasure in a newfound freedom from 'the discipline of work', although he had thoroughly enjoyed his time as a lecturer. A long-standing local politician and writer, he had strong ideas about how he wanted to spend his time and attractive alternative roles to pursue.

Even women who had been employed in fairly senior positions tended to stress that work was of secondary importance to their family lives. Mrs Napier, who had been a senior social work manager, described herself as 'not very 'career-minded' and having 'no ambition', saying 'I was quite happy at home with the children', while Mrs Norman, who worked in a senior local authority post, said that her central identity was a 'Jewish matron' and described her home as 'her life', while her job was 'just her job'. Following retirement, Mrs Napier returned to work part-time at a more junior level, as she enjoyed the day-to-day practice of social work, while Mrs Norman relished the chance to express other aspects of her identity, writing a book about Judaism, doing voluntary work with elderly Jewish people in Eastern Europe, and concentrating on home life.

Women who described work as more central to their lives often emphasised that it had been a financial necessity (complementing their partners' income). It is difficult to know how much this self-presentation resulted from normative pressures faced as working wives and mothers, but it appeared to be qualitatively different to the more 'vocational' attachment 
expressed by other informants. Several women commented that paid work had not been central to their identities because of societal attitudes prevailing during much of their working lives. Mrs McIntosh remarked that when she left school there were only three possible jobs for girls:

You either went into an office, became a nurse, or you went to university, which invariably just meant you became a teacher.

In any case, once married, 'you were expected to leave work and become a mum'. Although she later retrained, she found it impossible to break into her chosen field, and reflected that she 'never really had the kind of work [she] wanted'.

Fewer men than women expressed dissatisfaction with their jobs, or expressed an instrumental orientation (such as financial issues) to working. Those that did, however, were less traditionally gendered in their work identities, and found it easiest to adapt to being retired. Mr Fraser, who had taken early retirement after feeling increasingly unable to cope with the stress of his job as a computer programmer, commented:

Most people don't enjoy their jobs and probably wouldn't work if they didn't need the money.

Mr Adams, whose enjoyment of teaching had been soured by stress, decided that 'you shouldn't live to work, you should work to live,' and described the 
supply teaching he had done since retiring as 'purely for money'. Reflecting on his working life, he regretted the all-consuming nature of his commitment:

I mean, I worked, worked, worked, and I didn't spend enough time with my kids. We didn't do things because I was always working. It was a big problem. Even though you get these nice holidays. It doesn't compensate for the rest of the time.

A number of those interviewed had been or were involved in caring for someone, whether this was an ill or disabled partner, adult child, elderly parent or grandchildren, and this was often their reason for leaving paid work. While both men and women were affected in similar ways by these caring roles, more women than men took them on, and only women were involved in them for an extensive period of their lives. Caring in retirement, and caring as a significant influence on adaptation were distinctively feminised trajectories.

While people who had left work to provide care had done so willingly, this did not lessen their regret when they had enjoyed their jobs. Mr Kenny and his wife sold their shop to care for their son, who subsequently died. While he was grateful to have spent this time together, he described the decision as, 'slightly forced on us,' and said of his work, 'I missed it a great deal.' Mrs Lawson had decided to leave her managerial post to care for her parents 'virtually overnight.' While she unquestioningly adopted the role of carer, she experienced doubts about the work's legitimacy: 
It took me a while to get used to not going to my work and not having something to do like that because I felt looking after them wasn't really a job, if you know what I mean, although it was taking up all of my time it wasn't quite how I had planned things.

By contrast, for Mrs McRae caring had been her main 'career'. She was a widow who had stayed at home for many years caring for her children, moving on to care for her elderly mother and then her adult daughter (who had learning disabilities), while also caring part-time for her grandchild. For her 'retirement' was not a meaningful life stage in terms of changes to her identity or roles.

Several factors helped interviewees adjust to retirement and develop rewarding lifestyles. Those who adapted well tended to frame their experiences in terms of moving into retirement rather than as leaving work, and employed less dichotomous distinctions between these stages. Men who adopted more egalitarian gender roles tended to be more successful, as were more traditional women, particularly when 'retirement' provided an opportunity (or necessity) for them to take on more family responsibilities (although these gendered positions were also the product of particular class positionings). Interviewees who had planned for retirement and had strong ideas about the kinds of things they wanted to do, or who had established interests and priorities, tended to adjust well. The key was to regard retirement as an opportunity to do things unfettered by the demands of work, rather than as the 
end of an active life. Good existing social networks, located in the community or existing interests, helped in this adjustment.

\section{Older people's friendships}

Long (1987) has suggested that time spent with friends during retirement is related to whether relationships are associated with people's work or neighbourhood backgrounds. The curtailing of work-based social networks may be problematic, particularly where these have formed the basis of friendship groups. Jerrome has identified a gendered dimension in this:

Men's friendships tend to be sociable rather than intimate, and focused on shared activity. Women's friendships are characterised by emotional intensity and self-disclosure. ... Gender differences persist into old age, with women's relationships continuing to be more extensive and meaningful.

The women interviewed tended to have more intense friendships, emphasising affective dimensions, mutual support and reciprocity. Men's friendships were more often played out in the public sphere, and they depended more heavily upon children and partners for emotional support. Several married men referred to their wives as 'my best friend'. Exceptions to this included Mr Bevan, a long-term divorcee with a non-traditional gendered identity, who maintained close friends from his school days. Mr Johnson was 
more typical in seeing friends as people to share activities with rather than confidants:

We're still friends, you know we enjoy things together... I don't need a group of other chaps about to support me, I'm very much of a loner.

Those living in the former mining village frequently described close-knit friendships dating back many years. Mr and Mrs Jenkins had recently moved to the area, but found it easy to settle in and enjoyed close relationships with their neighbours, 'a nice little group in the street'. This contrasted with a number of those living in inner city London, who described the area as an unfriendly and even unsafe place.

Other factors mediating friendships included opportunity structures and mobility, which were linked to social class. Middle class interviewees more often had friends in other parts of the country (partly because of occupational mobility), whom they could afford to visit and take part in shared activities with. Middle class couples were also more likely to go to friends' houses for meals and on holidays together. By contrast, working class couples employed less individualistic narratives to describe their friendships, drew more heavily upon networks based in the community and at work, and were more likely to go to pubs and on outings with friends. Differences in the context of social activities were less marked for women, whose friendships were more often conducted in the private sphere. 
Opportunity structures for making friends were linked to all stages of life. Not working, not being involved in voluntary activities, illness and declining mobility, taking on caring responsibilities, and facing events experienced as 'shameful' (such as bankruptcy, divorce, homelessness and mental health problems) could all reduce opportunities for meeting new potential friends. Gender differences in the prevalence of these experiences reflected structural differences between men's and women's lives.

Social networks are often maintained and extended through partners. In the absence of partners, older people sometimes found their social networks curtailed. Several female interviewees felt it was socially difficult for single women to enter new public arenas, and had safety concerns about attending activities in the evening. Mrs Parker avoided night classes since she had been mugged, despite identifying a number she thought she would enjoy. For others, health problems could make it difficult to maintain relationships. Mrs Brown had recurring mental health problems that had caused her to leave several workplaces and lose touch with colleagues, and she found it difficult to establish reciprocal relationships with peers. A few women talked about difficulties meeting potential partners, and expressed fears that if they did so, men would expect them to adapt their lifestyle in undesired ways.

Older women are more likely to live on their own during retirement because of their greater longevity (Arber and Ginn 1991). In a sense, it is more expected that women will live alone, and support networks might be correspondingly more accessible to widowed women. Jerrome (1993) has 
suggested that women are better at making new relationships throughout life, so the disruption of widowhood is less extensive than for men (who rely more on spouses for intimacy), but this was not true for all. Mrs McRae had few close friends because a number had died and she had not made new friendships to replace those, partly because of her involvement in caring.

A small group of single people were among the most active during retirement. They found it easier to maintain rewarding relationships than those not involved in such activities. The lack of a live-in partner with their own interests, commitments or demands, meant that these men and women engaged in less negotiation of their time use, and could commit to more activities. They had also developed coping and interaction skills, which put them at an advantage in negotiating new social spaces in retirement. Mrs Ramsay described the importance of maintaining good relationships:

I think networking with people in any structure, of whatever it is, you know, of like-minded people, is really, really important. There's far too much isolation, that's why there's so many therapists, they're making a killing isn't it, with people's problems that they can't share, can't feel comfortable with family and with friends.

This capability was often linked to previous employment in sociable jobs, aspects of which were maintained in current non labour market activities. Mrs Ramsay had been involved in community and collaborative art projects throughout her life. Notably, she was Australian and spoke a great deal of the 
British 'reserve', suggesting that her more flexible deployment of feminine identity was related to her cultural positioning. As Skeggs (1997) has noted, gendered subjectivity is dialogic, and structural differences provide subtle distinctions in women's frames of references and henceforth in their gendered identities. In particular, discourses of 'respectability' restrict the range of femininities available to working-class women.

A number of women had assumed intensive caring roles, which were part of the traditionally gendered expectations about family care women had assimilated, providing intense emotional rewards and acute physical burdens. However, because these required temporal and physical proximity to the caredfor individual, they had the potential to restrict and damage social networks. These roles tended to be more comfortable for women to adopt when they drew upon fairly traditional notions of femininity and where paid work was less central to their identity.

\section{Adjusting to retirement: the effects upon marriage}

Around three-quarters of people in their fifties and early sixties are married or live with a partner (Matheson and Summerfield 1999), and this was also the case for our sample. Retirement is a time when the character of personal relationships undergoes qualitative change. Kulik's review of the literature (2001) suggests that the quality of marriage generally improves during retirement. However, there is also evidence of tension, for example, when one 
partner has health problems that jeopardise retirement plans, if retirement is unexpected, or where couples have different role expectations.

Although some US sources have considered the effect of retirement on couple relationships, most UK literature is concerned with individuals' adjustment. Because most women are younger than their partners, and because within older generations men's occupations, by virtue of their greater earning capacity, have tended to be prioritised, decisions about retirement are often triggered by 'his' retirement, rather than 'hers'. A husband or partner's retirement may lead a woman to retire herself, and some studies have suggested that simultaneous retirement is most likely to result in mutual satisfaction (Hurd 1990, cited in Hilbourne 1999). However, there might be strong reasons why a woman would wish to remain in work, especially if she has spent some years bringing up children; this may cause problems if wives feel pressurised into retiring.

Most interviewees reported an improvement in their marital relationships. This was particularly true of couples who had deliberately retired together, who pursued shared interests, and who had similar expectations about their gendered roles.

I think we got a lot closer, me and Janet. I'm in no doubt about that. A lot, lot closer. We just didn't have time for each other when we were running the business, doing fifteen hours a day. A lot, lot better. We 
can go where we want, do what we want, and we find it very nice! ( $\mathrm{Mr}$ Kenny)

Some people were aware they needed to maintain separate activities from their partners to sustain good quality relationships. Mrs Sampson explained:

I think we like our own space, you know. We don't like to live in each other's pockets ... we do do things together, and we go out a lot, you know, but it's nice to have our own space. You do need that. I wouldn't get anything done if he was under my feet all day!

Couples often described retirement as a time when they could refocus upon personal relationships and enjoy them for their own sake, rather than in terms of particular roles and obligations.

Retirement also saw a qualitative improvement in personal relationships where work had been a source of tension or impinged upon couples' time together. Mrs Norman recalled her relief to retire and not be constantly rushing between home and work, 'now it's lovely, he comes in and the house is warm and the dinner is ready and I'm happy'. Men, particularly where their partners still worked, found it helpful to develop their own active routines. Interviewees who devoted time to developing an equitable shift of responsibilities in retirement, which reflected their various commitments, reported feeling satisfied with personal relationships. 
Couple relationships could become strained immediately after leaving work where the retirement of one partner was unwanted or unexpected. Mrs Napier said her husband's reaction to redundancy had been so bad that, 'I felt he would have a breakdown' and their home life was difficult during this period. This transition could be more demanding when couples drew upon gendered expectations of employment (a male 'breadwinner'), and women described the adjustment as generally more difficult for men.

Some writers (Kulik 2001, 2002) argue that the retirement period may be marked by a decrease in role differentiation between married couples, and that negotiating increased equality in the division of domestic labour and marital power dynamics is important to the quality of marriage in later life, especially for women. The couples interviewed discussed the sharing of household tasks. These were often experienced as a source of stress immediately after retirement, particularly where women saw the home as their personal space and had preferred routines for household tasks.

When I get up I want to go and be doing my housework and he's saying, "What are you doing that for, it doesn't need doing," and it was, "I'm doing it, I'm in the habit of doing it." (Mrs Knox)

Where men had retired earlier than their partners, and become used to carrying out domestic tasks and regarding the home as their personal space, similar issues could arise for them, as this exchange illustrates: 
Mrs Denton: When I was in full-time employment and ...

Husband: I was happy. [laughs]

Mrs Denton: And Max was home, he sort of took responsibility for mostly everything, you know, to do with the daily running of the house, that's to say everything more or less, I mean ...

Husband: Now we're both here, we're miserable.

Mrs Denton: [Laughs] He was head cook and bottle washer.

While this couple made light of their situation, unresolved tensions were apparent. Mr Denton was in poor health and Mrs Denton had wanted to reduce her hours but had been unable to persuade her employers to agree, and had recently retired. They described themselves as 'on top of one another' and 'still in a period of adjustment'.

For Mrs Lawson, who had worked longer hours than her husband, her retirement meant that he had less to do around the house:

When I was working full-time then I was out all day, I mean some days I would go away at five o'clock in the morning and not be back 'til ten at night. I had a long, long day, so he would do the cooking and things like that, so it's kind of more shared now.

She anticipated a further phase of change to domestic routines when her husband retired, which he planned to do in about a year. These examples mirror Szinovacz's research (2000), which found that a husband who retired 
while his wife was still employed generally increased his involvement in tasks usually carried out by his wife, but reduced these again on her retirement. They highlight the social construction of a gendered division of domestic labour, and lend support to theories of equalisation in the retirement period.

When people living in couples were asked about household decisionmaking, most claimed to have an equal relationship where they discussed and negotiated before reaching a joint decision. In interviews where both partners were present, imbalances in power were often acknowledged in a joking way, as this quote illustrates:

Mrs Jenkins: We talk things over, don't we?

Mr Jenkins: Yeah, we have a brief discussion.

Mrs Jenkins: And then I decide!

For Mr Willis, decision-making was closely linked to his masculine identity as head of household:

Interviewer: On balance, who would you say has the last word? Mr Willis: Me, oh guaranteed. Well, I don't class myself as boss, but sort of head of the family sort of thing.

Other men, such as Mr Kamir, cheerfully acknowledged their willingness to defer to partners in the domestic sphere. A number of couples had adopted a gendered division of household decision-making, with women assuming 
responsibility for decisions relating to interior design and furnishing, while men dealt with organising holidays and decisions about purchasing items seen as having a 'technical' dimension. Some, like Mr Elkin, who was not entirely comfortable with a role at odds with his traditional concept of gender identity, explicitly referred to purchasing power as the determining factor influencing the balance of power within the couple relationship:

Again, it's not a normal way of working, I'm afraid. Because my wife has a good job, she would buy the washing machine, it's as simple as that, because she's paying for it.

Some of the women interviewed commented that they felt differently about finances once they retired. Mrs Maxwell explained how she had initially felt uneasy spending when she no longer felt she was making an economic contribution, but had been reassured by her husband:

When I first stopped working and l'd say to my husband, "I fancy such and such, can I buy it?" And he says, "Why all of a sudden are you saying 'Can I buy this?' You never did it before." And l'd say "Well..." And he said, "No, you just carry on just the same".

Health status was another area that could affect the balance of power in household decision-making, the negotiation of 'carer' and 'cared for' roles creating ambiguity and change. 


\section{The single person and retirement}

People living alone provide an interesting mobilisation of retirement, the absence of spousal expectations offering an opportunity for gender to be played out more flexibly. However, the literature suggests that marriage has a positive effect upon retirement satisfaction, although this is interlinked with more important psychosocial factors, such as health, involvement in activities and social contacts (Fernández-Ballesteros et al. 2001). Furthermore, the adoption of a single status may not be chosen, as for individuals who were widowed, whose partners left them, or who never found suitable life partners. In addition, focusing upon marriage excludes other significant relationships, which may be equally, if not more, emotionally rewarding than legally recognised relationships. 'Living together apart' relationships are receiving increased recognition as a preferred re-partnering choice in later life, and evidence suggests that women are often the driving forces in these arrangements (Borell and Karlsson 2002). Several interviewees lived on their own, but maintained on-going sexual relationships with partners in separate households. These all expressed satisfaction with their retirement. Only one considered moving in with their partner, and this man held traditional views about gender, identifying strongly as half a co-dependent couple: he had not lost the 'marital identity'. The maintenance of intense personal relationships on a flexible basis raises questions regarding whether older people conceptualise new relationships differently once family formation has ceased to be an issue. Mr Bevan had raised a daughter with his fiancé, and while they established a 
joint life together in terms of shared interests and friends, they had no plans to express this through a joint household. He explained,

We've been engaged seventeen years, no chance of getting married again now, no. We've got a relationship that works well and you don't rock the boat, no, we both have our own space, she comes on a Friday and she goes home on Monday.

About a quarter of those interviewed were single, being divorced, widowed or never married, and as in the broader population more women than men were single. Most lived on their own, and many were disabled or had long-term health problems. They were divided between those who were happy in their retirement, participating in a number of activities and enjoying rewarding relationships with friends, and those who had not adjusted well, taking part in fewer activities and feeling they lacked opportunities to broaden social circles. Health was not the mediating factor between these groups; more flexible ideas and expectations about gendered behaviour were linked to enhanced retirement satisfaction.

If retirement offers the opportunity to spend time in more rewarding ways, single people often found this was especially true, and many described a sense of fulfilment derived from feeling in control. Mrs Ramsay regarded retirement as a time when relationships of dependency faded, intimacy was enhanced, and she had more time for things she found enjoyable: 
This end of the life is better than the other end, in the sense that you don't have the responsibility for other people, your children and so on, so that's changed. It's a very relaxed time, in the sense of not having those responsibilities. I quite enjoy that, and this is just a new thing, so I'm still getting a buzz from it, because my youngest child has just turned 21, and I can take control of my life again, I'm able to let go. So it's quite an enlightening time I think, the later years, certainly in terms of the responsibilities.

Similarly Mrs Parker valued her abundance of time: 'I do what I want when I want. I don't have to answer to anyone, if I want to go out and not come back at a certain time.' Single women, particularly when they had lived alone for some time and engaged in low-paid work, often found retirement had little effect on their finances, having become adept at finding cost-free ways of spending their time. For Mrs Parker finding stylish clothes in jumble sales and growing her own vegetables was a financial necessity, but these had also become much enjoyed activities.

Single people described the opportunity to enjoy close friendships (quality being more important than the size of social circles) and to spend time on their own as important in achieving satisfying lifestyles. Despite the limits a heart attack imposed on his activities, Mr Bevan took pleasure in reinvigorated relationships with his friends, partner, family, neighbours, and grandchildren, 'the love of my life.' However, although he had a hectic social schedule, he also relished spending time alone, 'I tend not to let myself get bored, I like my 
own company, I love my own company. I'm alone but I'm not lonely.' Mrs Ramsay also talked about the importance of getting this balance right, 'I'm not out there all the time, I can spend two or three days in here and not see a soul and love it, you know I love my space, but it's nice to have a bit of choice.' Notably these individuals attributed their independence to their former occupations, having been sole providers, and mixing the statuses of selfemployment and employee pragmatically.

However, other single interviewees found loneliness was a problem. This was particularly true for women who had devoted a large amount of time caring for others, who found it difficult when those relationships ended. Mrs Wheeler had strongly identified as a single parent and foregone work for many years to concentrate on this role. Her daughter had recently left home, and she was clearly missing her a great deal and finding it difficult to renegotiate their relationship, feeling loth to impose upon her daughter's new household. Mrs Dinsmore received a lot of support from family and friends when her husband died, but explained that her pain coming to terms with widowhood was partly because she could no longer frame her identity in relation to her husband:

At the end of day, it's still you're on your own ... it's a big adjustment because I got married at twenty-one and l've never lived alone, so ... that's quite hard.

The assumption of this particular form of femininity, reliant upon a cared-for 'other', is potentially problematic since the absence of that person disturbs 
individuals' identity and sense of purpose. Relatedly, single people raised a fear of becoming dependent upon families.

\section{Conclusion}

In retirement, as throughout the lifecourse, men and women inhabit a range of gendered identities, mediated by class and ethnic differences. The ways men and women 'do' gender has implications for how they approach and adapt to retirement. Particular gendered roles were tied to particular work roles, which in turn were reflected in gendered roles adopted in retirement. Strong occupational identities had a particular capacity for making retirement painful when leaving work was not freely chosen, especially when individuals were involved in few outside activities and had no alternative identity to adopt in the absence of paid employment. This was equally true for men and women, a gendered issue only insofar as men were more likely to be strongly identified with paid work and conceptualise it in terms of a masculinised 'breadwinner' role. However, the interviewees most attached to their work valued different aspects, which had important implications for their gendered conceptions of identity: men tended to be more concerned with the loss of status, while more women described work as an important source of sociability.

In contrast, individuals who found it easier to leave work and adapt to retirement drew upon different gendered resources. Men who found the transition easiest tended to employ egalitarian ideas about relationships, had 
more resources with which to support preferred lifestyles, and employed individualistic narratives. By contrast, women's transitions were more often pre-empted or framed by pressing family demands, which provided at least one ready-made role in retirement. Women who took on heavy caring duties tended to find these more comfortably inhabited if they assumed traditional femininities.

The qualitative character of men and women's friendships was often distinctive, although mediated by social class and area differences. Women's close relationships tended to be more intimate, supportive and played out in the private sphere, while men's reflected shared interests and activities, and were based upon notions of companionship. The opportunity structures in which men and women developed friends were often quite different, and structural inequalities meant that some women enjoyed fewer chances to meet people.

The marital relationship was often an arena of change at the time of retirement, with most couples reporting an overall increase in intimacy after an initial period of adjustment. The distribution of household tasks and changes in the power balance of relationships were critical issues which could cause problems, particularly if couples adopted conflicting gendered identities or where men adhered to traditionally gendered expectations about employment. In most instances this was overcome by some degree of equalisation, although strongly gendered decision-making arrangements could also work well where both spouses were comfortable with and clear in their roles. 
Single men and women's responses to retirement were particularly distinctive and diverse. Some had poor experiences of retirement, which was often unchosen and characterised by little social participation. For these individuals retirement was often accompanied by the end of close relationships, a result of widowhood or the cessation of caring roles; these men and women tended to be those who had adopted quite traditional gendered identities. By contrast, a second group were among the most active interviewees and were more likely to maintain sexual relationships, take part in a range of activities, enjoy rewarding social relationships, and adopt flexible egalitarian ideas about gendered roles.

This paper has identified a range of gendered positions adopted by individuals as they move into retirement. Men and women who adopted a fluid approach to gendered assumptions, amending them to adapt to changes in the lifecycle, were more successful in achieving satisfying lifestyles. Class differences provide a fundamental mediating factor in the way people approach gender and their assets for inhabiting particular positions, as do cultural resources and traditions. Marital status also provides an important context for framing these identities. Reflecting divisions between public and private spheres in the organisation of productive activities, the conceptualisation of work and retirement as diametrically opposed is problematic. The people who achieved the most satisfying qualities of life were those who achieved some degree of continuity in their pre and post-retirement activities and relationships, for example, in terms of family care, voluntary work and friendship networks. 
However, among those interviewed, traditional gendered roles predominated, and for men these proved ill suited to adapting to retirement.

\section{References}

Arber, S. and Ginn, J. 1991. Gender and Later Life. Sage, London.

Barnes, H., Parry, J. and Lakey, J. 2002. Forging a New Future: The

Experiences and Expectations of People Leaving Paid Work Over 50. Policy

Press, Bristol.

Borell, K. and Karlsson, S. 2002. Reconceptualising intimacy and ageing.

Living apart together. Paper presented to the Reconceptualising Gender and Ageing conference at the University of Surrey, 25-27 June.

Bottero, W. 2000. Gender and the labour market at the turn of the century:

complexity, ambiguity and change. Work, Employment and Society, 14, 4, 78191.

Crawford, M. 1972. Retirement as a psychological crisis. Journal of Psychomatic Research, 16, 375-80.

Fernández-Ballesteros, R., Zamarrón, M.R. and Ruíz, M.A. 2001. The contribution of socio-demographic and psychosocial factors to life satisfaction. Ageing and Society, 21, 25-43.

George, L.K. 1993. Sociological perspectives on life transitions. Annual Review of Sociology, 19, 353-73.

George, L. and Maddox, G. 1977. Subjective adaptation to the loss of the work role: a longitudinal study. Journal of Gerontology, 39, 364-71. 
Isaksson, K. and Johansson, G. 2000. Adaptation to continued work and early retirement following downsizing: long-term effects and gender differences. Journal of Occupational and Organizational Psychology, 73, 241-56. Jerrome, D. 1993. Intimate relationships. In J.Bond, P.Coleman and S.Peace (eds.) Ageing in Society: An introduction to Social Gerontology. Sage, London, 226-54.

Kulik, L. 2001. Marital relations in late adulthood, throughout the retirement process. Ageing and Society, 21, 447-69.

Kulik, J. 2002. Marital equality and the quality of long-term marriage in later life. Ageing and Society, 22, 459-81.

Long, J. 1987. Continuity as a basis for change: leisure and male retirement. Leisure Studies, 6, 1.

Massey, D. 1995. The conceptualisation of place. In D.Massey and P.Jess (eds.) A Place in the World? Oxford University Press, Oxford.

Matheson, J. and Summerfield, C. (eds.) 1999. Social Focus on Older People. The Stationery Office, London.

Moen, P. 1996. A life course perspective on retirement, gender and well-being. Journal of Occupational Health Psychology, 1, 2, 131-44.

Parry, J. 2000. Class and identity processes: restructuring in the (former) coalmining communities of the South Wales Valleys. Unpublished PhD thesis, University of Southampton.

Parsons, T. 1942. Age and sex in the social structure of the United States. American Sociological Review, 7, 604-16. 
Phillipson, C. 1993. The sociology of retirement. In J.Bond, P.Coleman and S.Peace (eds.) Ageing in Society: An Introduction to Social Gerontology. Sage, London, 180-199.

Reitzes, D.C., Mutran, E.J. and Fernandez, M.E. 1998. The decision to retire: a career perspective. Social Science Quarterly, 79, 3, 607-19.

Richardson, I.M. 1956. Retirement: a socio-medical study of 244 men. Scottish Medical Journal, 1, 381-91.

Richardson, V. and Kilty, K. 1991. Adjustment to retirement: continuity vs discontinuity. International Journal of Ageing and Human Development, 33, $151-69$.

Skeggs, B. 1997. Formations of Class and Gender: Becoming Respectable. Sage, London.

Szinovacz, M. 1991. Women and retirement. In B.Hess and Markson, E. (eds.) Growing Old in America. Transaction Publishers, New York.

Szinovacz, M.E. 2000. Changes in housework after retirement: a panel analysis. Journal of Marriage and the Family, 62, 1, 78-92.

Szinovacz, M., Ekerdt, D.J., and Vinick, B.H. (eds.) 1992. Families and Retirement. Sage, Newbury Park, CA.

Tibbitts, C. 1954. Retirement problems in American society. American Journal of Sociology, 59, 301-8.

Work on this project was supported by the Joseph Rowntree Foundation. Financial support for writing this paper was provided by the University of Westminster's Regent Street Polytechnic Trust. Thanks to all those interviewed for generously giving their time to take part in this research. We 
are grateful to Steve Lissenburgh and the Employment Group at PSI for their comments on earlier versions of this paper.

\footnotetext{
${ }^{1}$ ACORN, the UK's original consumer classification, is used to segment the British population in terms of consumer and lifestyle characteristics. ACORN combines geography with demographic data from the 1991 Census to classify the GB population into 17 groups, which are subdivided into 54 types.

${ }^{2}$ Social class position was determined on the basis of (former) occupation, housing tenure and social attitudes.

${ }^{3}$ A computer software package for the analysis of qualitative data.
} 